\title{
PUNIDOS POR ENVELHECER
}

\author{
Raimunda Silva d' Alencar*
}

\section{Resumo}

Este artigo tem o propósito de analisar a questão da violência contra pessoas idosas na cidade de Itabuna, sul do Estado da Bahia, a partir de denúncias recebidas pelo Conselho Municipal do Idoso. Os casos denunciados, e apurados na pesquisa, refletem o abandono em que se encontram as famílias por parte do poder público, e dão conta de que a violência contra idosos se associa aos frágeis vínculos afetivos construídos por essas famílias, bem como a desvinculação social a que são submetidas, que os reproduzem na convivência familiar cotidiana. Os idosos dependentes de cuidadores acabam sendo as vítimas do descaso do poder público, cada vez mais incapaz de garantir vinculação e pertencimento social a muitos brasileiros, e dos transitórios valores incorporados pelos jovens, onde o idoso não tem espaço.

Palavras-chave: Violência. Maus Tratos. Envelhecimento.

\section{Introdução}

A Constituição brasileira de 1988, no seu artigo primeiro, coloca em evidência a cidadania como um dos fundamentos do Estado democrático. Isto significa dizer que o indivíduo participa da sociedade brasileira não só ajudando-a, mas dela recebendo apoio para desenvolver-se e viver dignamente (BRASIL, 1988). Trata-se de um conceito que tem ocupado lugar de destaque, não só nos discursos políticos ou acadêmicos, mas na linguagem popular, estando organicamente ligado à idéia de direitos.

Cidadania e direitos são, na verdade, noções que atendem a uma historicidade, o que significa que, a cada momento, atribuímo-lhes novas determinações. Assim, de Aristóteles a Marx, passando por Locke, Rosseau e Kant, o conteúdo desse conceito já não é o mesmo. Da mesma forma, os

\footnotetext{
Professora Assistente da Universidade Estadual de Santa Cruz/ Departamento de Filosofia e Ciências Humanas (UESC/DFCH), Coordenadora do Núcleo de Estudos do Envelhecimento e do Curso de Especialização em Gerontologia Social. Ilhéus, Bahia, 2005.E-mail: young2004@ig.com.br
} 
direitos fundamentais, aspiração de todo ser humano, embora presentes e garantidos nas Constituições brasileiras, também já não têm o mesmo conteúdo.

Recorrendo ainda à Constituição Brasileira, o seu artigo 230 se volta à velhice como fator de atenção obrigatória. Nesse artigo, sabiamente, fica definido que a família, a sociedade e o Estado têm responsabilidades, devendo amparar e dar retaguarda a homens e mulheres, no seu envelhecimento (BRASIL, 1988). Embora essa previsão constitucional exista, não se pode desconsiderar que a família, apesar de hoje precisar da ajuda do idoso no sustento dos seus membros, tem deixado de ser o espaço físico e afetivo tão necessário ao desenvolvimento saudável do idoso, que, aos poucos, vem perdendo lugar dentro do núcleo familiar. A sociedade, por outro lado, mantém-se com valores que parecem não levar mais em conta a experiência dos mais velhos, enaltecendo a juventude e o consumismo a que ela se associa, tratando com indiferença aqueles que não se encaixam nesse quadro. $O$ Estado, cada vez mais distanciado do bem-estar social, afasta-se dos compromissos básicos que garantiam ao cidadão comum a inclusão na sociedade de pertencimento.

Garantidos no plano constitucional e reforçados no conteúdo das Leis 8.842 (BRASIL, 1994) e 10.741 (BRASIL, 2003), esse amparo e proteção, na prática, não parecem tão assegurados quando a questão é abuso e maus tratos sofridos pelo idoso ${ }^{1}$. Conciliar cidadania com as múltiplas formas de violência e violações de direitos que constituem o cotidiano dos segmentos mais fragilizados da população brasileira é hoje um grande desafio, que a sociedade precisa incorporar.

Para compreender as múltiplas formas com que se expressa, é importante compreender, em primeiro lugar, que a violência se inscreve muito além da ordem econômica, como sinalizada por muitos estudos. Perpassando diferentes camadas sociais, a violência incorpora uma dimensão valorativa, o que significa dizer que está inscrita na ordem simbólica das relações humanas, inclusive mobilizando sentimentos de medo, ódio, frustração, ressentimento, angústia, mas também de afeto e amor. Em segundo lugar, é preciso levar em conta que a violência contra o idoso é muito mais comum do que se imagina; acontece em qualquer classe social ou grupo religioso, com pessoas saudáveis ou incapacitadas, sendo mais incidente nestes últimos (MINAYO, 2003; MENEZES, 1999).

\footnotetext{
1 Maus tratos compreendido como ação capaz de produzir dano à integridade física ou psíquica do idoso, seja no meio familiar, comunitário ou institucional, intencionalmente ou não; incluída a omissão (CORDONNIER; TABERA; OLIVERA, 2000).
} 
Quando a imprensa brasileira divulgou, no mês de novembro de 2002, imagens de uma doméstica maltratando uma idosa até levá-la a óbito, a população manifestou grande surpresa e ficou chocada diante das cenas. Por ser um problema pouco estudado na nossa realidade, ainda causa impacto e é possível que pessoas resistam a acreditar na sua existência corriqueira, principalmente porque os idosos não denunciam e sofrem, silenciosamente, as violências e maus tratos, não só de desconhecidos, mas de familiares.

A tentativa de identificar os maus-tratos e abusos a que são submetidos os idosos na realidade brasileira, e no espaço sul-baiano em particular, esbarra em muitas dificuldades. Além de pouco consideradas, até mesmo pelos profissionais da saúde, que vêm tendo uma contribuição efetiva na identificação de casos de violência contra crianças, as notificações de violência contra o idoso ficam a desejar, não apenas pela falta de locais para registro dessas denúncias e pela pouca importância dada à questão, mas, principalmente, pelo conceito de violência dominante na população, inclusive nas organizações locais e entre profissionais, quase sempre reduzido a danos físicos e morte.

Procurado por vezes para ajudar idosos em situação de dificuldades, o Conselho Municipal do Idoso de Itabuna $(\mathrm{CMI})^{2}$ recebeu informações de que: a) comerciantes de gêneros alimentícios, na periferia da cidade de Itabuna, estariam retendo cartões de benefícios/aposentadoria de idosos em troca dos alimentos de que necessitam para sobreviver;

b)idosos estariam enfrentando agressões e maus tratos dentro dos seus próprios lares e em organizações prestadoras de serviços.

Dado o acelerado envelhecimento da população local, e o reconhecimento das precárias condições sob as quais vive parte significativa dessa população, essas questões passaram a merecer uma atenção especial do Conselho, no período 2003-2004, a partir de quando desencadeou algumas ações objetivando conhecer de perto a situação e buscar possíveis encaminhamentos para minimizar o sofrimento das vítimas. Nesse sentido, foi desenvolvida uma frente de trabalho contando com sistemático apoio do Ministério Público local e de uma assistente social, cujas ações se pautaram:

a) na observação da violência em hospitais e postos de saúde distribuídos em vários bairros da cidade;

2 Trata-se de situação difícil de confirmar, pelo medo e pelo entendimento de que o comerciante "[ ... e é bonzinho e só quer ajudar." 
b) no recebimento de denúncias de violência contra idosos em domicílio, feitas por qualquer cidadão, pessoalmente ou por telefone, no caso do denunciante não querer se identificar.

Com base, pois, nas informações do Conselho, este estudo se propõe a conhecer e analisar esta segunda questão - a violência em domicílio -, tomando como elementos de análise os dados recolhidos pelo próprio Conselho, em função das denúncias recebidas.

Para este estudo, portanto, utilizou-se a ficha do Conselho Municipal do Idoso para registro das denúncias recebidas, no período de maio de 2003 a junho de 2004, além de relatórios técnicos elaborados pela assistência social quando de suas visitas domiciliares para averiguação da denúncia e encaminhamento ao Ministério Público. Apesar de encaminhadas à Promotoria Pública através de ofício, pedindo solução, o Conselho procurava - com os recursos humanos de que dispunha - apurá-la ${ }^{3}$ através de visita domiciliar, de conversa com a família e idoso, pela Assistente Social ${ }^{4}$.

Nessa ficha de registro de denúncias, foram consideradas as seguintes variáveis:

a) pela vítima: idade, sexo, endereço completo, grau de escolaridade, número de filhos, renda e origem dela;

b) pelo agressor: idade, grau de parentesco com a vítima, ocupação;

c) conteúdo da agressão.

Nem todas as fichas estão com todos os campos preenchidos, o que promove dificuldades na consideração de todos os casos, além do que, a apuração tem ritmo lento para ocorrer. A partir da organização dos dados, 49 fichas consideradas, foi possível fazer visitas domiciliares em quatro dos casos, com o objetivo de verificar in loco a situação denunciada, acompanhando a Assistente Social em seu trabalho.

\section{Traduzindo (ou Situando) a Violência contra Idosos}

Não representa qualquer novidade, e é quase uma unanimidade, que a violência vem imperando ou que ela está em toda parte, produto de uma crise plena das dimensões política, social e econômica das relações humanas,

3 Apenas os casos que, a priori, não dependessem de investigação policial (casos de envolvimento com drogas, por exemplo).

4 Inclusive porque a idéia do Conselho, de acordo com seus dirigentes, é fazer um trabalho educativo e de diálogo com as famílias, não apenas puni-las, por entender que também elas são vítimas da negligência do Estado e do caráter fragilizado do que normalmente se entende por cidadania. 
que castiga duramente amplos setores sociais. Dentro desse contexto, um grande número de pessoas pertencentes aos setores mais vulneráveis da população, como crianças, pessoas incapacitadas, mulheres e idosos, são excluídos do sistema social. Estes grupos são os que mais sofrem violência social, nas suas múltiplas facetas.

Os estudos sobre a violência nas cidades brasileiras tornam-se cada vez mais presentes nas publicações especializadas, além de ser tema de registro cotidiano na mídia, na pauta de preocupação de políticos e intelectuais, e no pensamento da população, que se vê cada vez mais insegura onde quer que esteja, até mesmo em casa, lugar onde se espera proteção e segurança. É comum a afirmação de que a violência pertence ao cotidiano; está presente no trânsito, no trabalho, nas ruas, nas escolas, nos lares.

Embora essa presença seja hoje fortemente reconhecida, é preciso compreender que a violência " [ ... ] tem uma história, tanto quanto tem uma geografia e uma sociologia, e que assume formas diferentes em períodos diferentes." (BURKE, 2002, p. 35). Essa visão é confirmada por Michaud ${ }^{5}$ apud Costa, que entende a violência como " [... ] aquilo que as sociedades consideram como tal e varia de uma cultura e de uma sociedade para outra e também conforme o momento histórico vivido", e por Mareuse (2004, p. 89), para quem

[...] a violência não se caracteriza por um ato ou fato, mas possui diferentes interfaces. Em diferentes sociedades ou em diferentes momentos ela recebe valorizações diferentes, sendo tolerada, proibida, encorajada ou despercebida, e sua definição está principalmente atrelada a esse âmbito de análise, uma vez que essas interfaces são construídas através de representações e estas envolvem diferentes momentos, lugares, pessoas.

A violência contra os grupos mais vulneráveis tem seu correlato na repulsa social, e a resposta tem sido dada pela sensibilização de pessoas que, pela profissão ou pela ligação com os mais diferentes setores comprometidos com o problema, começam a estabelecer estratégias de ação. Esses setores, na sociedade de Itabuna, são representados pelos conselhos (de saúde, do idoso), pelo ministério público, ou pelos cidadãos que ainda conseguem se indignar.

${ }^{5}$ MICHAUD, Yves. A Violência. São Paulo: Ática, 1989. Apud COSTA, 1999, p. 5. 
O idoso dependente, portador de algum tipo de patologia, seja ela de média ou longa duração, com dificuldades de locomoção, ou mesmo aquele com algum tipo de limitação mental, ou depressão, são os mais vulneráveis à violência e aos maus tratos, não apenas junto aos familiares e cuidadores, mas, também, junto às organizações assistenciais.

As famílias, cada vez mais modificadas na sua constituição e fragilizadas nas suas relações, cujos membros vivem situações marginais sem precedentes, vêm se constituindo em zona frágil para os apoios relacionais e afetivos tão necessários aos sujeitos em idade avançada. Dentro desse contexto, em que as transformações econômicas fazem o deslocamento de valores, fica evidenciada a atomização da estrutura social, da mesma forma que fica evidenciada a exclusão, do sistema social, de segmentos pertencentes a setores mais vulneráveis da população, onde se encontra o idoso.

Tomando as situações marginais definidas por Castel (1997), a partir de processos de desligamento, em relação ao trabalho (estável, precário e não-trabalho) e à interação social (forte, frágil e isolamento) ${ }^{6}$, e do agrupamento dessas diferentes gradações, é possível considerar que a violência doméstica, seja ela física ou psicológica ${ }^{7}$, não pode ser considerada apenas no âmbito da dimensão econômica, ainda que não seja desprezível a sua importância enquanto elemento definidor de comportamentos e de atitudes frente à vida e frente ao outro.

Embora seja tema de difícil conceituação teórica, por força da complexidade que incorpora, Michaud $^{8}$ apud Mareuse, afirma que

[ . . . ] há violência quando, numa situação de interação, um ou vários atores agem de maneira direta ou indireta, maciça ou esparsa, causando danos a uma ou várias pessoas em graus variáveis, seja em sua integridade física,

\footnotetext{
6 O autor considera três zonas: a) de integração, quando há forte interação social e trabalho estável; b) de vulnerabilidade, quando há trabalho precário e frágeis apoios relacionais; c) de marginalidade ou de desfiliação, quando há ausência de trabalho e isolamento social; e) da assistência, quando o sujeito é um indigente inválido e sobrevive da caridade.

7 A violência física inclui qualquer ação com intuito de produzir lesão corporal ou dor à outra pessoa, e inclui empurrões, puxões de cabelo, beliscões, apertos, torção, bofetadas, socos, chutes, batidas contra a parede, queimaduras, dentre outros. A violência psicológica tem a intenção de produzir dano psicológico ou dor emocional à outra pessoa e inclui medo, humilhação, perda da alta estima, desespero, sentimento de culpa, insegurança, incapacidade. (MORRISON; BIEHL, 2000, p. 50).

${ }^{8}$ MICHAUD, Yves. A Violência. São Paulo: Ática, 1989.Apud MAREUSE, 2004, p. 90.
} 
seja em sua integridade moral, em suas posses ou em suas participações simbólicas e culturais.

Assim, a violência contra o idoso se expressa nos estereótipos negativos, na desqualificação como pessoas, a exemplo de "sujeito ultrapassado", "velho não serve", dentre outros, além das lesões corporais, negligência, descaso. Em geral, está expressa quando cuidadores (familiares ou amigos) se apoderam dos recursos econômicos do idoso (como aposentadorias, pensões, benefícios) ou não utilizam esses recursos que pertencem ao idoso em benefício do próprio idoso. É comum que cartões bancários fiquem em mãos de familiares/cuidadores, e os idosos nunca recebam um centavo do dinheiro sacado. Mais recentemente, com a enorme campanha publicitária de disponibilização de crédito para o aposentado, idosos estão sendo enganados com empréstimos que comprometem parte significativa do que ganham, durante dois-três anos, e não ficam com o dinheiro porque, em geral, são os portadores dos cartões do idoso (familiares, amigos) que acabam se beneficiando do tal empréstimo.

Se é corriqueira a expropriação de valores, também o é de propriedades, com argumentos nem sempre verdadeiros de que o idoso não tem condição para administrá-los; quando o idoso é isolado com argumentos equivocados de que não se interessa mais pelas conversas, de que prefere ficar só, de que não escuta mais, de que não entende o que outros falam, também isto se constitui uma forma de violência. Além disso, há a vergonha de que vizinhos e amigos descubram doenças de que o idoso é portador.

Naturalmente, várias outras formas podem ser consideradas, a exemplo de ameaças, tratamento infantilizado, agressões verbais do tipo "lerdo", "imprestável”, empurrões para "andar rápido" quando o idoso não tem condição de fazê-lo, beliscões, isolamento do idoso do convívio familiar no horário das refeições, impedimento de manifestar preferência por alimentos de que gosta, a permanência em casa sem nunca sair para um passeio com familiares ou, ainda, a indisponibilidade da família para conversar com o idoso.

Fora isso, há que se considerar os horários rígidos de banho, de dormir/acordar, de refeições, que representam uma forma de agressão ao direito de liberdade do idoso para escolher os horários que lhe convém ou o alimento que deseja, naturalmente que dentro das possibilidades de saúde. Um exemplo dessa rigidez pode ser visto quando da permanência de idosos em organizações hospitalares ou asilares, com horários predeterminados para a refeição, o banho, ainda que o idoso não esteja com vontade de fazê-lo. 
Mas isso não ocorre só nas organizações, mas nos domicílios também, em especial quando o idoso perde a capacidade de realizar as atividades da vida diária. Ser obrigado a morar ora com um filho ora com outro, dividir quarto com pessoas desconhecidas, não ter privacidade para usar um sanitário, tomar banho ou vestir-se frente a pessoas com as quais não compartilha qualquer relação afetiva, ter a sua higiene íntima feita por pessoas do sexo oposto (situação que ocorre normalmente em organizações hospitalares) são situações que normalmente interferem negativamente no seu equilíbrio emocional ou os deixam constrangidos. Retirar o idoso do espaço onde esteve por longos períodos da sua vida, sem ao menos consultá-lo, é, também, uma forma de violência.

\section{As Vulnerabilidades da Velhice}

Em uma sociedade estruturada de forma fragmentada, seletiva e restritiva em termos de consumo, o envelhecimento da população vai ser produzido como reflexo dessa dinâmica.

Nesse sentido, é recorrente considerar o envelhecimento como uma questão social relevante, não só devido às especificidades desta etapa da vida, mas por conta do impacto que esse envelhecimento traz, colocando em evidência as fragilidades dos indivíduos que envelhecem, e da própria sociedade de pertencimento desse idoso, que também envelhece.

É fato que as ações e políticas sociais disponibilizadas a esse segmento etário da população, embora com consideráveis avanços, não têm acompanhado o nível das demandas, considerando as manifestações orgânicas, psíquicas e sócio-culturais produzidas pelo envelhecimento, conseqüência de um estilo de vida em fases pretéritas. A predominância e o visível aumento de grupos de pessoas convivendo em permanente estado de carência ao longo da vida, excluídos do acesso a condições básicas como moradia digna, acesso à saúde, disponibilização de água potável, alimentação de qualidade e em quantidade necessária, acesso à informação, cultura, lazer, dentre outros, tem sido historicamente a tônica da sociedade brasileira, e pode estar comprometendo seriamente a velhice atual e futura dos sujeitos que a integram.

Além dos problemas estruturais historicamente enfrentados pela população, surgem e se intensificam os problemas de ordem conjuntural, que enfraquecem e fragilizam cada vez mais as relações sociais. O governo encontra dificuldades para alocar recursos capazes de prover a velhice, principalmen- 
te com uma aposentadoria em níveis que permitam ao idoso viver com dignidade. Assim, o enfrentamento de desafios e dificuldades para adquirir materiais que proporcionem uma vida prazerosa, pois recebem aposentadorias irrisórias, não condizem com os anos de trabalho. Os municípios não conseguem dar conta de uma saúde preventiva, aquela que leve em conta as necessidades básicas de alimentação, água, saneamento, ambiente saudável, moradia.

Mesmo assim, não se pode secundarizar o fato de que a expectativa de vida do brasileiro vem aumentando, o que não significa que o Brasil tenha padrão e qualidade de vida nos níveis desejados para toda a sua população. Considerando esses aspectos, não é de se estranhar que pessoas vivendo mais tempo, se tornem também mais vulneráveis e dependentes ${ }^{9}$, impondo a necessidade de políticas sociais pontuais capazes de minimizar as tensões que se estabelecem entre indivíduos e grupos, onde as famílias se encontram.

As políticas sociais brasileiras, especialmente aquelas que se propõem a dar amparo à velhice, foram ampliadas a partir dos anos noventa, especialmente quando as estatísticas passam a dar conta de um acelerado crescimento da população idosa. Na verdade, a Constituição de 1988 insere o disparador em favor da velhice (vide artigos 203 e 230), inclusive atribuindo à família a responsabilidade primeira no dever de amparar e proteger o idoso (BRASIL, 1988). A questão é que grande parte das famílias brasileiras se encontra em desamparo por parte do Estado, cujas políticas econômicas não garantem emprego e não permitem a manutenção de um padrão de vida digno.

A partir daí, a Lei Orgânica de Assistência Social (LOAS), em 1993, passa a assegurar um salário mínimo mensal ao cidadão idoso, a título de benefício; a Lei 8.842, em 1994, garante ao idoso os direitos sociais e assegura (embora não garanta) a criação das condições para a promoção da autonomia do idoso, sua integração e participação efetiva na sociedade, a criação de Conselhos do Idoso e, finalmente, o Estatuto do Idoso.

É natural que leis e portarias estaduais e municipais complementem o reconhecimento de uma crescente preocupação do Estado com o idoso brasileiro, que precisa ser olhado como cidadão. ${ }^{10}$ É nessa direção que a Lei Municipal 1.787, de maio de 1999, criou o Conselho do Idoso de Itabuna,

9 Estatísticas dão conta de que mais de $85 \%$ dos idosos brasileiros apresenta, pelo menos, uma enfermidade crônica (BRASIL, 2002).]

${ }^{10}$ De acordo com Herkenhoff (2002, p. 3), “[ . . . ] cidadão é o indivíduo que está no gozo dos direitos civis e políticos de um Estado." 
Bahia. Trata-se de uma cidade situada ao sul do Estado da Bahia, com aproximadamente 220 mil habitantes e, destes, quase vinte mil maiores de sessenta anos. Não se tem conhecimento de qualquer programa especial desenvolvido pelo poder público local voltado para esse segmento da população.

4 Os Idosos e a Violência: seu conteúdo e espacialização

A violência contra os idosos desta pesquisa, no município de Itabuna, Bahia, não é anônima; a vítima tem nome, família, renda, endereço. A idade média dos idosos considerados vítimas de agressão, nesta pesquisa, está em torno de 72 anos.

Os agressores, que também têm nomes e endereços, são em geral os próprios familiares (filhos, filhas, afilhados, netos, genros, noras), mas se incluem também vizinhos e conhecidos, têm idades entre 16 e 75 anos, com ocupações que variam do comerciário, passando pelo feirante, motaxista, estudante, manicure, corretor de imóveis, vigilante, do lar. Mas inclui um número significativo de desempregados, cerca de $20 \%$ dos casos considerados.

As características da violência, expressas no conteúdo das denúncias, traduzem as situações de conflitos vividos pelas famílias, cotidianamente violentadas pela ausência de condições mínimas de sobrevivência, falta de moradia decente, falta de saneamento básico, falta de emprego.

A maioria dos idosos, nas condições em que foram encontrados, é duplamente vitimizada, tanto pela estrutura social, quanto pela estrutura familiar. As situações de desemprego, as condições de desnutrição, o consumo de drogas (alcoolismo e outros tipos), a deterioração dos vínculos afetivos na família propiciam a existência de padrões de conduta agressivos para a resolução de conflitos cotidianos na família.

Dos 49 casos de denúncia recebidos pelo Conselho Municipal do Idoso de Itabuna, apenas seis idosos moram sozinhos. Nos demais, as condições de vida das famílias são precárias, as moradias são pequenas para a quantidade de moradores, algumas camas não têm colchão, e o benefício ou aposentadoria se constitui na única renda ${ }^{11}$. Alguns casos a seguir são ilustrativos:

a) Sra. M.., 64 anos, diabética, uma perna amputada, necessitando de cuidado médico e de terapia medicamentosa constantes. Mãe de

${ }_{11}$ Em cerca de $20 \%$ dos casos analisados encontrou-se idosos em estado de desnutrição, sem medicação (embora alguns sejam diabéticos, hipertensos), sem assistência de qualquer natureza, apesar do programa de saúde pública (Programa de Saúde da Família). 
três filhos, a idosa recebe benefício de um salário mínimo, mora em barraco de tábua, sem energia, sem água, sem sanitário. Uma filha, de 32 anos, que afirma "não ter jeito para tratar de doentes", sem outra ocupação, tem a posse do cartão, saca o benefício mas não o utiliza em benefício da mãe, que passa necessidades e vive da caridade de vizinhos. Os irmãos, por conta desse benefício de um salário mínimo, agredem-se freqüentemente. Um dos filhos, sem trabalho, consumidor de drogas, veio a falecer no período deste levantamento, vítima de homicídio; a idosa não suportou e faleceu logo depois;

b) Sra. Id.... 100 anos, morava com um neto, que veio a falecer. Uma amiga foi morar com ela e levou seu companheiro. Essa amiga sofreu um derrame e está sendo cuidada pela família, há três anos, em outro local. O parceiro da amiga, que não tinha para onde ir, permaneceu morando na casa da idosa, transformando-se no seu agressor, embora não tenha qualquer parentesco com ela. De posse do cartão, deixa-a desassistida de medicamento e de alimentação. Desempregado, tornou-se dependente químico e transformou a residência da idosa em ponto de uso e venda de drogas, mantendoa presa, sem chances de contato com vizinhos, que silenciam a situação da idosa com medo do agressor, considerado violento;

c) Sra. MI..., 87 anos, aposentada, não sabe quanto ganha, mora só. O agressor é seu afilhado, tem 60 anos, é um micro-comerciante. Tem a posse do cartão e, além de deixá-la só, sem qualquer assistência ou companhia, ainda mantém a casa trancada, no cadeado, para evitar visitas de vizinhos;

d) Sr. Ax..., 86 anos, mora com filho de 26 anos, desempregado e envolvido com drogas. Além de exigir mensalmente $30 \%$ do benefício de um salário mínimo que o idoso recebe, esse filho ainda o agride fisicamente e o ameaça com faca.

O que une os quatro casos é, de um lado, a ausência de trabalho para familiares dos idosos em idade ativa e a omissão do poder público com políticas compensatórias para o desemprego, o que traduz uma clara negação de cidadania para as famílias. De outro lado, percebe-se que a presença de consumo de drogas, particularmente em três dos quatro casos citados, reflete os vazios deixados pelo poder público nesses espaços e vida dessas pessoas, possibilitando a existência de uma "zona de marginalidade" para essas famílias, para quem já não há trabalho, mas há forte isolamento social, como quer Castel (1997). 
De acordo com esse autor, os idosos dos exemplos acima se enquadrariam na "zona da assistência", considerados indigentes inválidos e sobreviventes da caridade ${ }^{12}$, ainda que exista o benefício da LOAS, na verdade funcionando como única renda para os mais jovens que não conseguem emprego. A questão é que a cidade de Itabuna dispõe de três asilos, que funcionam em precárias condições, mas onde, certamente, os idosos estariam melhor que em seus lares. No entanto, os "cuidadores" não os liberam, motivados pelo benefício previdenciário de que se apropriam, única renda a lhes garantir pertencimento social, e da qual efetivamente depende toda a família, além do que, integrantes do Conselho do Idoso interpretam a obrigatoriedade da família na assistência e cuidados aos seus idosos, e repetem que lugar de idoso é junto dos familiares, mesmo nos casos em que esses vínculos parecem não mais existir, admitindo-se terem existido no passado.

As denúncias registradas são oriundas de bairros periféricos da cidade $^{13}$ (à exceção de um deles que é de classe média alta), sendo que alguns apresentaram índices maiores de casos de denúncia. Tratam-se de bairros com estrutura de urbanização ainda precária, assinalando-se deficientes serviços, como linhas de ônibus, energia, disponibilização de água (cuja distribuição é precaríssima), telefonia, ruas pavimentadas, algumas com saneamento, ainda que as moradias dessas famílias aqui consideradas sejam absolutamente precárias, parte delas sem água encanada, sem energia, sem banheiros, sem vasos sanitários.

Embora não se possa estabelecer uma relação linear entre pobreza e violência, esses idosos - com suas famílias - sofrem privações múltiplas e acabam sendo vítimas, pela intolerância e pelo desrespeito, da reprodução do não reconhecimento dos direitos do outro.

Não se pode reduzir, no entanto, os efeitos da fragilidade dos vínculos familiares e dos processos interativos entre indivíduos e entre estes e seus ambientes sociais concretos. A fragilização dos vínculos afetivos e das práticas solidárias, quase sempre configuradas na ajuda mútua, é visível inclusive na vizinhança desses idosos. Além disso, esse idoso, também um "desfiliado"

\footnotetext{
12 “Quando não se é um cidadão e não se tem meios de sê-lo, só se pode viver da boa vontade dos outros" (CARRETEIRO, 2001, p. 163).

13 Califórnia, Santo Antonio, São Caetano, Santa Inês, Sinval Palmeira, Pedro Jerônimo, Fátima, Mangabinha, Conceição, São Pedro, Caixa d’ Água, Fonseca, Jardim Vitória, Vila de Mutuns, Urbis 4, Novo Horizonte, Sarinha, Zizo, São Roque, Zildolândia. Os dois primeiros apresentaram os maiores números de casos, e o último é bairro de classe média alta.
} 
(por não mais possuir uma carteira de trabalho que o identificava e o reconhecia), se encontra desvalorizado social e familiarmente, desamparado publicamente (alguns residem próximos a postos de saúde, por exemplo, mas nunca receberam a visita de profissional da área) e sem condições de efetivar trocas de favores, que sustentam as práticas solidárias.

\title{
PUNISHED FOR AGING
}

\begin{abstract}
This article has the intention of analyzing the matter of the violence against aged people in the city of Itabuna, southern Bahia state, from denunciations received by the city council. The denounced cases and the ones which were found out in the research reflect how public power treats the elder's families. It also reflects that the violence against aged is associated with the fragile affective bonds constructed by these families, as well as the social disconnection which they are submitted. The aged who is under somebody's care can be victim of the public indifference, that is, each time more incapable to guarantee entailing and social belonging to many Brazilians, and victim of the transitory values incorporated by young people, where the aged one does not have space.

Keywords: Violence. Maltreatment. Aging.
\end{abstract}

\section{REFERÊNCIAS}

BRASIL. Constituição (1988). Constituição da República Federativa do Brasil: promulgada em 5 de outubro de 1988. Brasília: Senado Federal, 1988.

BRASIL. Ministério da Saúde. Redes Estaduais de Atenção à Saúde do Idoso. Guia Operacional e Portarias Relacionadas. Brasília, DF, 2002.

BRASIL. Lei $n^{\circ} 10.741$, de $1^{\circ}$ de outubro de 2003. Decreta e sanciona o Estatuto do Idoso. Salvador: Ministério Público do Estado da Bahia, 2003.

BRASIL. Lei n ${ }^{\circ} 8.842$, de 4 de janeiro de 1994. Decreta e sanciona a Política Nacional do Idoso, cria o Conselho Nacional do Idoso e dá outras providências. Salvador: Ministério Público do Estado da Bahia, 1994. 
BURKE, Peter. Violência Urbana e Civilização. In: OLIVEIRA, Nilson Vieira (Org.). InSegurança Pública: reflexões sobre a criminalidade e a violência urbana. São Paulo: Nova Alexandria, p. 32-50, 2002.

CARRETEIRO, Teresa Cristina. Perspectivas da Cidadania Brasileira: entre as lógicas do direito, do favor e da violência. In: ARAUJO, José Newton Garcia de.; CARRETEIRO, Teresa Cristina (Org.). Cenários Sociais e Abordagens Clínicas. São Paulo: Escuta; Belo Horizonte: FUMEC, p. 155168, 2001.

CASTEL, Robert. A Dinâmica dos Processos de Marginalização: da vulnerabilidade à desfiliação. Caderno CRH, Salvador, n. 26/27, p. 19-40, jan./dez. 1997.

CORDONNIER, María Pura; TABERA, Elisabet María; OLIVERA, Ivana Ethel. Maltrato hacía los ancianos: delimitación del problema y propuesta de abordage desde el trabajo social. Tiempo, Buenos Aires, n. 6, nov. 2000.

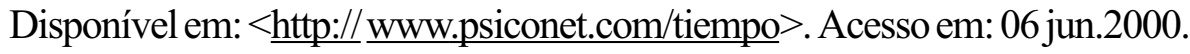

COSTA, Márcia Regina da. A Violência Urbana é Particularidade da Sociedade Brasileira? São Paulo em Perspectiva. São Paulo, v. 13, n. 4, p. 3-12, out./dez. 1999.

HERKENHOFF, João Batista. Cidadania para Todos: o que toda pessoa precisa saber a respeito de cidadania. Rio de Janeiro: Thex, 2002.

MAREUSE, Márcia Aparecida Giuzi. Reflexões sobre a Violência, suas Manifestações na Mídia e Implicações no Universo Infanto-Juvenil. CADERNOS - Centro Universitário São Camilo, São Paulo, v. 10, n. 4, p. 28-32, out./dez., 2004.

MENEZES, Maria do Rosário de. Da Violência Revelada à Violência Silenciada: um estudo etnográfico sobre a violência doméstica contra o idoso. 1999. 385 f. Tese (Doutorado em Enfermagem) - Universidade de São Paulo, Escola de Enfermagem de Ribeirão Preto, Ribeirão Preto,1999. 
MINAYO, Maria Cecília de Souza. Violência contra Idosos: relevância para um velho problema. Cadernos de Saúde Pública, Rio de Janeiro, v. 19, n. 3, p. 783-791, 2003.

MORRISON, Andrew R.; BIEHL, Maria Loreto (Org.). A Família Ameaçada: violência doméstica nas Américas. Rio de Janeiro: FGV, 2000. 